\title{
Therapeutic Anticoagulation Prevalence among Patients of a Cardiology Clinic receiving Warfarin and Association with Overweight
}

\author{
KS McKenzie ${ }^{1}$, JE Campbell ${ }^{1}$, A Procope ${ }^{1}$, VE Elliott ${ }^{2}$, C Wilson-Clarke ${ }^{1}$, M Gossell-Williams ${ }^{1 *}$ \\ ${ }^{1}$ Pharmacology Section, Department of Basic Medical Sciences, University of the West Indies \\ ${ }^{2}$ Consultant Cardiologist, Department of Medicine, University Hospital of the West Indies
}

Received: March 29, 2016; Accepted: April 20, 2016; Published: April 21, 2016

*Corresponding author: M Gossell Williams, Pharmacology Section, Basic Medical Sciences, University of the West Indies, Mona Campus, Kingston 7, Jamaica West Indies, Tel: 876-927-2216; Fax: 876-977-3823; E-mail: maxine.gossell@uwimona.edu.jm

\begin{abstract}
Introduction: Warfarin is the main anticoagulant therapy offered in Jamaica; however, no published data is available evaluating prevalence of therapeutic anticoagulation among this population.

Methods: A cross-sectional study conducted at the Cardiology Clinic of the University Hospital of the West Indies from January 2014-May 2014 and February 2015-October 2015 of patients on warfarin therapy for more than one month and a self-report of good compliance. International Normalized Ratio (INR) was obtained by one drop of capillary blood applied to CoaguChek XS Plus monitor; age, ethnicity, gender, warfarin dose were recorded and body mass index (BMI) was calculated.
\end{abstract}

Results: Of the 65 subjects, most were of Afro-Caribbean ethnicity $(\mathrm{n}=60)$, predominantly females $(44 ; \chi 2=8.1, \mathrm{p}=0.004)$, median age was 59 (range 26-91) years and the median BMI was 26.7 (range $18.8-45.0 \mathrm{~kg} / \mathrm{m}^{2}$ ). Daily warfarin doses range from 2.5 $\mathrm{mg}$ to $10.0 \mathrm{mg}$. Therapeutic anticoagulation (INR of 2.0-3.0 or 2.03.5 , dependent on condition) was observed in 17 (26.2\%) subjects; significantly more of the subjects, $48(73.8 \%)$, presented with nontherapeutic INR $(\chi 2=14.8 ; p<0.001)$. BMI was positively correlated with therapeutic INR (Spearman's rho $=0.28 ; \mathrm{p}=0.027$ ). Subjects within the therapeutic INR had significantly higher median BMI, 30.2 (interquartile range $=11.8 \mathrm{~kg} / \mathrm{m}^{2}$ ) than subjects with non-therapeutic INR, 26.0 (interquartile range $=7.4 \mathrm{~kg} / \mathrm{m}^{2}$ ) (Mann-Whitney test, $\mathrm{p}=0.028$ ), however there was no difference in the warfarin dose between groups.

Conclusions: There is a high prevalence of non-therapeutic anticoagulation among subjects in this study. Subjects with therapeutic anticoagulation were significantly overweight, suggesting a need to further examine the relationship between overweight and vitamin $\mathrm{K}$ status in this population.

Keywords: Warfarin; Therapeutic anticoagulation; INR; CoaguChek® XS Plus; Body mass index

\section{Introduction}

Warfarin is an anticoagulant used extensively in the prevention of thromboembolic events for a variety of conditions relating to the cardiovascular system [1]. It inhibits the enzyme
Vitamin K epoxide reductase which is essential for the formation of reduced vitamin $\mathrm{K}$, a co-factor for the hepatic synthesis of the clotting factors II, VII, IX and X [2].

The outcome of warfarin therapy varies among individuals due to factors such as genetics, age, ethnicity, diet and weight which have been shown to have varying impact on therapeutic anticoagulation [3-10]. Although many studies have reported benefits of the use of these parameters to determine warfarin doses, clinically guided management still relies heavily on monitoring International Normalized Ratio (INR).

The primary objective of the study was to examine the prevalence of therapeutic anticoagulation with warfarin among patients registered in a setting where clinically guided management is the only available system for monitoring warfarin efficacy. The secondary objectives of the study include an assessment of the differences between subjects that are within the target INR range (therapeutic anticoagulation) and those subjects outside the target INR (non-therapeutic anticoagulation).

\section{Methods}

This was a cross-sectional, observational, convenience sample study of adults (at least 18 years of age) on warfarin maintenance therapy recruited from the University Hospital of the West Indies Cardiology Clinic in the two time periods (January 2014- May 2014 and February 2015 - October 2015). Inclusion criteria also required subjects to be warfarin for more than one month and self-report of good compliance. Informed consent guidelines were followed and all subjects recruited in this study consented to participate.

After Informed Consent was obtained, information recorded included daily dose, date of initiation, and indication for warfarin therapy. Also recorded for each subjects was age, weight, height, gender, ethnicity and concomitantly administered drugs.

\section{INR assessment}

A single sample of one drop ( $\geq 8 \mu \mathrm{L}$ ) of capillary blood from each patient, obtained by pinprick was used to obtain INR 
using the Roche Diagnostic CoaguChek XS Plus system. The CoaguChek XS Plus system is a point-of-care system that consists of a CoaguChek XS Plus monitor and CoaguChek XS Plus PT test strips and produces results within seconds. The test strip consist of lyophilized reagents, thromboplastin and a peptide substrate[11,12] and has an INR measuring range from 0.8 to 8.0 with $97 \%$ accuracy when compared to lab results [13].

\section{Data analysis}

The BMI was calculated with the formula: BMI= weight $(\mathrm{kg}) /$ square of height $\left(\mathrm{m}^{2}\right)$. Subjects were grouped along BMI classification of underweight (BMI $<18.5 \mathrm{~kg} / \mathrm{m}^{2}$ ), normal weight (BMI $18.5-24.9 \mathrm{~kg} / \mathrm{m}^{2}$ ), overweight (BMI $25-29.9 \mathrm{~kg} / \mathrm{m}^{2}$ ) and obese (BMI $\geq 30 \mathrm{~kg} / \mathrm{m}^{2}$ ).

Subjects were classified as having therapeutic INR when INR was in the range of 2.0 to 3.0, except in the case of high risk mechanical prosthetic valves and systemic recurrent emboli, where the range is 2.0 to 3.5. These ranges are based on recommendation by the American Heart Association for antithrombotic therapy [14].

Descriptive statistic of mean \pm standard deviation (SD) and median and Interquartile range (IQR) values for continuous data and proportions for counts was used for demographics. Continuous data was assessed for normal distribution. Chisquare $(\chi 2)$ goodness of fit with degrees of freedom (df) was used to analyse significant differences between proportions. Subjects were divided dichotomously into obtaining therapeutic INR (2.03.0 and 2.0-3.5) and INR out of range and comparison between groups made using Mann-Whitney for continuous data and Fisher's exact test for nominal data. Spearman's rho was used to evaluate correlations. Statistical significance was accepted when $\mathrm{p}<0.05$.

\section{Results}

In total, 68 subjects consented to participate in the study; however, 65 were included in the data analysis, as data was missing for 3 subjects. Afro-Caribbean ethnicity $(n=60)$; was significantly more represented and 5 were of Indian ethnicity $(\chi 2=46.5 ; \mathrm{df}=1 ; \mathrm{p}<0.001)$. Females were significantly more represented than males ( 44 females; $\chi 2=8.1, \mathrm{df}=1 \mathrm{p}=0.004$ ). The age of the subjects ranged between 26 years and 91 years; mean age of the group was $58.3 \pm 15.5$ years and the median age was 59.0(24) years; age was found to be normally distributed. BMI was only calculated for 61 of the subjects, as 4 subjects were wheelchair bound (no weight measured) giving a mean of $27.7 \pm 6.1 \mathrm{~kg} / \mathrm{m}^{2}$ and median of $26.7(7.8) \mathrm{kg} / \mathrm{m}^{2}$; BMI was not normally distributed. Of the subjects with BMI calculated, 25 were of normal weight, while 17 subjects were overweight and 19 were obese, however there was no significant difference in proportions across body weight $(\chi 2=1.7 ; \mathrm{df}=2 ; \mathrm{p}=0.426)$.

Period on warfarin therapy for subjects extended beyond a year for most subjects $(n=42)$. Table 1 lists the indication for warfarin therapy; most of the subjects were being managed for atrial fibrillation. The warfarin dose ranged from $2.5 \mathrm{mg}$ to $10 \mathrm{mg}$ with the median dose being 6.1 (2.0) $\mathrm{mg}$. There was no
Table 1: List of the indications for warfarin for subjects $(n=65)$ recruited in the study.

\begin{tabular}{|l|l|}
\hline Indication for Warfarin & Frequency \\
\hline Atrial fibrillation & 23 \\
\hline Cardiac valve replacement & 17 \\
\hline Valvular repair/ Atrial fibrillation & 3 \\
\hline Rheumatic heart disease & 10 \\
\hline Atrial flutter & 3 \\
\hline Deep vein thrombosis/ Pulmonary embolism & 4 \\
\hline Apical thrombus & 2 \\
\hline Cardioembolic stroke & 2 \\
\hline Unstable angina & 1 \\
\hline
\end{tabular}

correlation between warfarin dose and age, gender or BMI. Three subjects were taking warfarin only; concomitant drugs included diuretics (59), inhibitors of the renin angiotensin system (36), beta blockers (29), digoxin (29), statins (22), calcium channel blockers (9), anti-platelets (11) and anti-diabetic (13). Subjects fully compliant with warfarin therapy were significantly more represented, as 50, reported not missing any dose of warfarin $(\chi 2=56.7 ; \mathrm{df}=2 ; \mathrm{p}<0.001)$, while 11 subjects indicated missing 1 to 3 doses per month and 4 missing more than 3 doses per month.

Significantly more of the subjects in this study, 48(73.8\%), presented with non-therapeutic INR values and 17 (26.2\%) subjects were identified to have INR in therapeutic range $(\chi 2=14.8 ; \mathrm{df}=1, \mathrm{p}<0.001)$ with 25 below INR target and 23 having INR above target. Analysis between these groups with age, gender warfarin dose and BMI, showed only BMI to have a small positive correlation with subjects achieving therapeutic INR range (Spearman's rho $=0.28 ; n=61 ; p=0.027$ ). On further assessment for difference between the groups, subjects within the therapeutic INR range had significantly higher median BMI, $30.2\left(11.8 \mathrm{~kg} / \mathrm{m}^{2}\right)$, than subjects with non-therapeutic INR, $26.0\left(7.4 \mathrm{~kg} / \mathrm{m}^{2}\right)$ (Mann- Whitney test, $\left.\mathrm{p}=0.028\right)$. There was no difference in age, gender or the warfarin dose between subjects achieving therapeutic INR range and those with non-therapeutic INR Table 2.

\section{Discussion}

This study examined the prevalence of therapeutic anticoagulation among patients treated at a cardiology clinic where warfarin remains the most common anticoagulant prescribed. Given the major complications that can occur with non-therapeutic anticoagulation $[15,16]$, it is of concern that $73.8 \%$ of the subjects in this study presented with nontherapeutic anticoagulation, all of whom have been on warfarin therapy for more than one month and most for more than one year.

Therapeutic anticoagulation correlated with increasing BMI and assessment of differences between subjects showed that subjects with therapeutic anticoagulation were overweight or obese. Furthermore, although previous studies suggest that larger doses of warfarin are required with increasing body 
Table 2: Comparison of parameter between subjects with therapeutic anticoagulation (Therapeutic INR) and non-therapeutic anticoagulation (nonTherapeutic INR).

\begin{tabular}{|c|c|c|c|}
\hline $\begin{array}{l}\text { Demographics \& Medical } \\
\text { information }\end{array}$ & $\begin{array}{l}\text { Therapeutic INR } \\
(n=17)\end{array}$ & Non-Therapeutic INR $(n=48)$ & $\begin{array}{l}\text { p value } \\
\text { Mann-Whitney or Fisher's } \\
\text { exact tests }\end{array}$ \\
\hline \begin{tabular}{|l|} 
Age (years) \\
Mean (SD) \\
Median (IQR)
\end{tabular} & $\begin{array}{l}56.7(16.0) \\
55.0(28.0)\end{array}$ & $\begin{array}{l}58.8(15.4) \\
59.0(24.0)\end{array}$ & 0.754 \\
\hline \begin{tabular}{|l} 
Gender \\
Male \\
Female
\end{tabular} & $\begin{array}{l}8 \\
9\end{array}$ & $\begin{array}{l}13 \\
35\end{array}$ & 0.145 \\
\hline $\begin{array}{l}\text { BMI }\left(\mathrm{kg} / \mathrm{m}^{2}\right) \\
\text { Mean (SD) } \\
\text { Median (IQR) }\end{array}$ & $\begin{array}{l}(n=14) \\
31.1(7.4) \\
30.2(11.8)\end{array}$ & $\begin{array}{l}(n=47) \\
26.5(5.2) \\
26.0(7.4)\end{array}$ & $0.028^{*}$ \\
\hline $\begin{array}{l}\text { Warfarin dose (mg) } \\
\text { Mean (SD) } \\
\text { Median (IQR) }\end{array}$ & $\begin{array}{l}5.9(2.1) \\
6.5(2.5)\end{array}$ & $\begin{array}{l}6.1(1.9) \\
5.00(2.5)\end{array}$ & 0.786 \\
\hline
\end{tabular}

weight $[17,18,19]$, there is no evidence from this study to suggest such an association.

Limited reports examining the association of therapeutic coagulation with BMI exist; therefore the finding in this study requires further exploration. Similar findings were reported from a subset of patients for the AMADEUS trial; for 814 aging patients ( $\geq 75$ years old) on warfarin therapy, therapeutic anticoagulation (measured as percentage time in therapeutic INR) was reported to be more likely in obese patients [20].However, whether overweight improve warfarin efficacy requires more exploration into dietary factors, specifically, vitamin $\mathrm{K}$ status.

While the liver is a storage site for vitamin $\mathrm{K}$, sequestration in adipose tissue has also been identified as significant to vitamin $\mathrm{K}$ regulation [21,22]. Shea, et al. examined vitamin K status among 142 aging men and women. After controlling for dietary vitamin $\mathrm{K}$ intake, the study showed that there is poorer plasma vitamin $\mathrm{K}$ status and less availability of hepatic vitamin $\mathrm{K}$ with increasing adipose tissue [22]. Shea et al. further suggested that adipose storage has a functional role in regulating plasma and hepatic vitamin K status; however this functional role is yet to be fully elucidated. We hypothesize that adipose tissue acts a reservoir to regulate plasma and hepatic vitamin $\mathrm{K}$ homeostasis, thus facilitating improved therapeutic anti-coagulation with warfarin.

This is the first report to assess warfarin efficacy in Jamaican patients; however, the small sample size and reliance of patient recall of compliance are factors of this study that limit the findings related to age, gender and warfarin doses. A longitudinal study design to facilitate calculation of time spent in therapeutic anticoagulation may have provided a more robust measure of therapeutic anticoagulation than a single time point reading. The study findings are also limited by the non-assessment of co-morbidities. Additionally, co-administered drug information collected was inadequate to facilitate assessment of the impact on warfarin therapy.

In conclusion, non-therapeutic anticoagulation was the more likely presentation among the subjects of this study; given the complication of poor anticoagulation, more research in this patient group is required and should include exploring factors contributing to finding of therapeutic anticoagulation among overweight subjects.

\section{Acknowledgement}

The authors wish to thank Ms. Chantelle Barrett for her contribution to the study and Hoffmann-La Roche (Pharma Jamaica) for their donation of the CoaguChek XS Plus machine.

\section{Ethical Approval}

This study was conducted based on ethical principles outlined by the Declaration of Helsinki and was reviewed and approved by the University of the West Indies Ethics Committee.

\section{References}

1. Kuruvilla M, Gurk-Turner C. A review of warfarin dosing and monitoring. Proc (Bayl Univ Med Cent). 2001;14(3):305-306.

2. Schwarz UI, Stein, CM. Genetic determinants of dose and clinical outcomes in patients receiving oral anticoagulants. Clin Pharmacol Ther. 2006;80(1):7-12.

3. Limdi NA, Brown TM, Yan Q, Thigpen JL, Shendre A, Liu N, et al. Race influences warfarin dose changes associated with genetic factors. Blood. 2015;126(4):539-545. doi: 10.1182/blood-2015-02-627042.

4. Marie AY, Bostwick JR, Hallman IS. Warfarin Drug Interactions: Strategies to Minimize Adverse Drug Events. J Nurse Pract. 2011;7(6): 506-512. doi.org/10.1016/j.nurpra.2011.03.002.

5. Fiumara K, Goldhaber SZ. A Patient's Guide to Taking Coumadin/ Warfarin. Circulation. 2009;119:e220-e222. doi: 10.1161/ CIRCULATIONAHA.108.803957.

6. Whitley HP, Fermo JD, Chumney EC., Brzezinski WA. Effect of patientspecific factors on weekly warfarin dose. Ther Clin Risk Manag. 2007;3(3):499-504

7. Hirsh J, Dalen JE., Anderson DR., Poller L, Bussey H, Ansell J, et al. Oral anticoagulants: mechanism of action, clinical effectiveness, and optimal therapeutic range. Chest. 2001;119(1 Suppl):8S-21S.

8. Roth JA, Boudreau D, Fujii MM, Farin FM, Rettie AE, Thummel KE, 
et al. Genetic Risk Factors for Major Bleeding in Patients Treated With Warfarin in a Community Setting. Clin Pharmacol Ther. 2014;95(6):636-643. doi: 10.1038/clpt.2014.26

9. Suarez-Kurtz G, Botton MR. Pharmacogenomics of warfarin in populations of African descent. Br J Clin Pharmacol. 2013;75(2):334346. doi: 10.1111/j.1365-2125.2012.04354.x.

10. Gong IY, Schwarz UI, Crown N, Dresser GK, Lazo-Langner A, Zou G, et al. Clinical and genetic determinants of warfarin pharmacokinetics and pharmacodynamics during treatment initiation. PLoS One. 2011;6(11):e27808. doi: 10.1371/journal.pone.0027808.

11. Plesch W, Van den Besselaar AM. Validation of the Internationa Normalized Ratio (INR) in a New Point-of-Care System Designed for Home Monitoring of Oral Anticoagulation Therapy. Int J Lab Hematol 2009;31(1):20-25. doi: 10.1111/j.1751-553X.2007.00998.x.

12. National Institute for Health and Care Excellence, NICE Guidance London: National Institute for Health and Care Excellence (UK); Atrial fibrillation and heart valve disease: self monitoring coagulation status using point of care coagulometers (the CoaguChek XS system and the INRatio2 PT/INR monitor). [Cited 2016 March 27]; Available from: https://www.nice.org.uk/guidance/dg14/chapter/4-Thediagnostic-tests

13. CoaguChek, Products and Solutions. Indianapolis. [Cited 2016 March 27]; Available from http://coaguchek-usa.com/products-andsolutions/

14. Hirsh J, Fuster V, Ansell J, Halperin JL. American Heart Association/ American College of Cardiology Foundation guide to warfarin therapy. J Am Coll Cardiol. 2003;41(9):1633-1652.
15. Sam C, Massaro JM, D’Agostino RB Sr., Levy D, Lambert JW, Wolf PA, et al. Warfarin and aspirin use and the predictors of major bleeding complications in atrial fibrillation (the Framingham Heart Study). Am J Cardiol. 2004;94(7):947-951.

16. Barta AL, Nutescu EA, Thompson PA, Bussey HI, Gulseth MP. Relationship between time spent at extreme International Normalized Ratios and time in therapeutic range with bleeding and thrombosis in warfarin-treated patients. Am J Health Syst Pharm. 2015;72(14):1188-1194. doi: 10.2146/ajhp140752.

17. Mueller JA., Patel T, Halawa A, Dumitrascu A, Dawson NL. Warfarin dosing and body mass index. Ann Pharmacother. 2014;48(5):584588. doi: $10.1177 / 1060028013517541$.

18. Kabagambe EK, Beasley TM, Limdi NA. Vitamin K Intake, Body Mass Index and Warfarin Maintenance Dose. Cardiology. 2013;126(4):214218. doi: 10.1159/000354218.

19. Self TH, Wallace JL, Sakaan S, Sands CW. Effect of Body Weight on Dose of Vitamin K Antagonists. South Med J. 2015;108(10):637-643.

20. Senoo K, Lip Gregory Y.H. Body Mass Index and Adverse Outcomes in Elderly Patients With Atrial Fibrillation:The AMADEUS Trial. Stroke. 2016;47:523-526. doi: 10.1161/STROKEAHA.115.011876.

21. Oldenburg J, Marinova M, Müller-Reible C, Watzka M. The Vitamin K cycle. Vitam Horm. 2008;78:35-62. doi: 10.1016/S00836729(07)00003-9.

22. Shea MK, Booth SL, Gundberg CM, Peterson JW, Waddell C, DawsonHughes B, et al. Adulthood obesity is positively associated with adipose tissue concentrations of vitamin $\mathrm{K}$ and inversely associated with circulating indicators of vitamin $\mathrm{K}$ status in men and women. J Nutr. 2010;140(5):1029-1034. 